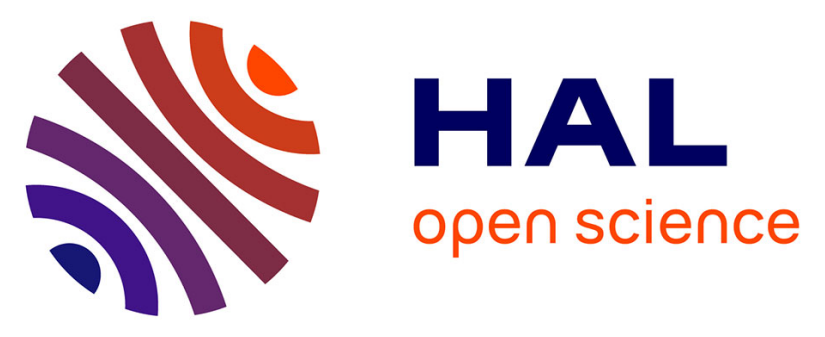

\title{
New therapeutic perspectives to manage refractory immune checkpoint-related toxicities
}

Filipe Martins, Gerasimos P Sykiotis, Michel Maillard, Montserrat Fraga,

Camillo Ribi, Thierry Kuntzer, Olivier Michielin, Solange Peters, Georges

Coukos, Francois Spertini, et al.

\section{To cite this version:}

Filipe Martins, Gerasimos P Sykiotis, Michel Maillard, Montserrat Fraga, Camillo Ribi, et al.. New therapeutic perspectives to manage refractory immune checkpoint-related toxicities. Lancet Oncology, 2019, 20, pp.e54 - e64. 10.1016/S1470-2045(18)30828-3 . hal-03486412

\section{HAL Id: hal-03486412 \\ https://hal.science/hal-03486412}

Submitted on 20 Dec 2021

HAL is a multi-disciplinary open access archive for the deposit and dissemination of scientific research documents, whether they are published or not. The documents may come from teaching and research institutions in France or abroad, or from public or private research centers.
L'archive ouverte pluridisciplinaire HAL, est destinée au dépôt et à la diffusion de documents scientifiques de niveau recherche, publiés ou non, émanant des établissements d'enseignement et de recherche français ou étrangers, des laboratoires publics ou privés.

\section{(c) (1) $\$$}

Distributed under a Creative Commons Attribution - NonCommercial| 4.0 International 


\title{
New therapeutic perspectives to manage refractory immune checkpoint-related toxicities: personalized treatment algorithms beyond corticosteroids
}

\author{
Filipe Martins MD ${ }^{1,2}$, Gerasimos P. Sykiotis MD-PhD ${ }^{3}$, Michel Maillard MD-PhD ${ }^{4,5}$, \\ Montserrat Fraga MD ${ }^{4}$, Camillo Ribi $\mathrm{MD}^{6}$, Thierry Kuntzer $\mathrm{MD}^{7}$, Olivier Michielin MD- \\ $\mathrm{PhD}^{8}$, Solange Peters MD-PhD ${ }^{8}$, Georges Coukos MD-PhD ${ }^{8,9}$, Francois Spertini MD \\ John A. Thompson MD ${ }^{10,11}$, Michel Obeid MD-PhD ${ }^{6,12,13^{*}}$
}

${ }^{1}$ Centre hospitalier universitaire vaudois (CHUV), Service et laboratoire central d'hématologie, département d'oncologie, rue du Bugnon 46, CH-1011 Lausanne, Switzerland

${ }^{2}$ School of Life Sciences, Ecole Polytechnique Fédérale de Lausanne (EPFL), CH-1015 Lausanne, Switzerland

${ }^{3}$ Centre hospitalier universitaire vaudois (CHUV), service d'endocrinologie, diabétologie et métabolisme, avenue de la Sallaz 8, CH-1011 Lausanne, Switzerland

${ }^{4}$ Centre hospitalier universitaire vaudois (CHUV), service de gastro-entérologie et hépatologie, rue du Bugnon 46, CH-1011 Lausanne, Switzerland

${ }^{5}$ Crohn's and Colitis Center Lausanne, avenue Jomini 8, CH-1004 Lausanne, Switzerland

${ }^{6}$ Centre hospitalier universitaire vaudois (CHUV), service immunologie et allergie, rue du Bugnon 46, CH-1011 Lausanne, Switzerland

${ }^{7}$ Centre hospitalier universitaire vaudois (CHUV), service de neurologie, rue du Bugnon 46, CH-1011 Lausanne, Switzerland

${ }^{8}$ Centre hospitalier universitaire vaudois (CHUV), département d'oncologie, rue du Bugnon 46, CH-1011 Lausanne, Switzerland

${ }^{9}$ Ludwig Institute for Cancer Research, chemin des Boveresses 155, CH-1066 Epalinges, Switzerland

${ }^{10}$ Fred Hutchinson Cancer Research Center, Seattle, Washington, USA

${ }^{11}$ National Cancer Institute/NIH, Bethesda, Maryland, USA

${ }^{12}$ Université Pierre et Marie Curie, faculté de médecine Pitié-Salpêtrière, centre hospitalouniversitaire Pitié-Salpêtrière, 91 Boulevard de l'Hôpital, F-75013 Paris, France

${ }^{13}$ Centre hospitalier universitaire vaudois (CHUV), centre d'immunothérapie et de vaccinologie, rue du Bugnon 17, CH-1011 Lausanne, Switzerland 


\section{*Corresponding author:}

Michel Obeid, MD, PhD

Centre hospitalier universitaire vaudois (CHUV)

Centre d'immunothérapie et de vaccinologie, Rue du Bugnon 17, 1011 Lausanne, Switzerland Email: michel.obeid@chuv.ch

\section{KEY WORDS}

Checkpoint inhibitors, CTLA-4, Immune-related adverse events, irAEs, PD-1, PD-L1

\section{ABBREVIATIONS}

AAG

AIDs

$\mathrm{AIH}$

AIT

CTLA-4

ICIs

IBD

$\operatorname{irAE}(\mathrm{s})$

IS

mAbs

PD-1

PD-L1

SLE

SJS
Autoimmune autonomic ganglionopathy

Autoimmune disorders

Autoimmune hepatitis

Autoimmune toxicity

Cytotoxic T lymphocyte-associated antigen 4

Immune-checkpoint inhibitors

Inflammatory bowel disease

Immune-related adverse event(s)

Immunosuppression

Monoclonal antibodies

Programmed death 1 receptor

Programmed death-ligand 1

Systemic lupus erythematosus

Stevens-Johnson syndrome 


\begin{abstract}
Immune-checkpoint inhibitors (ICIs) are reshaping the prognosis of many cancer types and are progressively becoming a standard of care for many of them. Cancer immunotherapy has started a revolution in the oncology therapeutic landscape, bringing new hope to patients but also a whole new spectrum of toxicities for practitioners to manage. Oncologists and specialists involved in the pluridisciplinary management of immune-related adverse events (irAEs) are increasingly confronted with the therapeutic challenge of severe and/or refractory cases. In this personal view, we propose new therapeutic strategies to manage them. Based on current knowledge of irAE pathogenesis and our immunological expertise, we transpose the use of new biologic and non-biologic immunosuppressive agents, used to treat primary autoimmune disorders (AIDs), in the context of severe and/or steroid refractory irAE management. Depending on the immune-type predominant infiltrate, we elaborate personalized treatment algorithms beyond corticosteroids. A "shut-off” strategy, intended to treat severe or steroidrefractory irAEs, based on the efficient inhibition of key inflammatory components involved in their pathophysiological processes, and limit potential adverse effects of drug immunosuppression on tumor response is proposed. This approach goes beyond current guidelines, challenging the step-by-step increase in drug immunosuppression proposed so far.
\end{abstract}




\section{INTRODUCTION}

Monoclonal antibodies that block immune checkpoints, such as the cytotoxic T-lymphocyte antigen 4 (CTLA-4)-CD28 and programmed death 1 (PD-1)-programmed death ligand 1 (PDL1) axes, are the main immunotherapies prescribed in the current oncological practice. Over the last decade, clinicians have been confronted with the management of irAEs resulting from ICI therapies. Because of the increasingly widespread use of ICIs in oncology, new data on toxicities related to these agents are continuously reported, in addition to the ones documented in prospective clinical trials. The advent of double checkpoint inhibition constitutes also a new challenge as the related toxicities often involve multiple organs and occur at higher frequencies compared to monotherapy. For example, the prospective Checkmate 067 trial on ipilimumab/nivolumab combination in advanced melanoma reported a $4 \%$ incidence of patients with steroid-refractory irAEs. ${ }^{1}$ The spectrum of organ systems affected by irAEs is very broad and their management often requires expertise that goes beyond the specialty of oncology. They vary in frequency and severity, depending on the agent(s) and the affected system(s). Consequently, their optimal management requires experienced multidisciplinary teams. Extensive knowledge in the field of clinical immunology and immunosuppressive therapy, going beyond current guidelines, is often required of such teams. Another crucial challenge is the need for early recognition and prompt treatment of irAEs to avoid adverse outcomes due to delayed patient care. Like most treatment-related toxicities in oncology, irAEs should be managed according to grade. Nevertheless, one should not overlook the limitations of current grading systems, and thus should not to substitute them for clinical judgment, especially in frail patients and when confronted with rapidly evolving irAEs. In this personal view, we discuss personalized therapeutic options for severe and/or refractory irAEs, based on current immuno-pathophysiological knowledge and on extrapolations from primary autoimmune counterparts.

High-quality guidelines regarding the management of irAEs were released by the European Society of Medical Oncology (ESMO) ${ }^{2}$, the National Comprehensive Cancer Network (NCCN) and the Society for Immunotherapy of Cancer (SITC) Toxicity Management Working Group. ${ }^{3,4}$ They provide treatment algorithms for most frequent irAEs in a comprehensive way and detail their recommendation regarding the use of immunosuppressive drugs according to irAE severity and duration. They also emphasize the importance of avoiding delays in the work-up to rule-out other differential diagnoses (e.g., infectious complications or tumor 
progression) before initiating effective immunosuppressive therapy. However, as exhaustive as these guidelines can be, they are still limited regarding the management of severe and/or refractory irAEs, with which clinicians are confronted in the day-to-day practice. Retrospective data on a large ipilimumab-treated cohort reported that more than one-third of patients received corticosteroids to manage an irAE, and one-third of those required additional immunosuppressive drugs. ${ }^{5}$ It is important to be aware that rare yet life-threatening irAEs are constantly reported, representing a diagnostic and therapeutic challenge; for such irAEs, evidence to guide management recommendations is limited due to the scarcity of literature, consisting of only small series or case reports. Some experts are already adopting a first instance cytokine-directed therapy, such as tocilizumab (an IgG1 humanized anti-IL6R mAb), in steroid-refractory cases. ${ }^{6}$

\section{NEW THERAPEUTIC PERSPECTIVES TO MANAGE ICI-INDUCED TOXICITIES}

Due to the scarcity of prospective trials regarding drug immunosuppression in the setting of high-grade irAEs, in daily clinical practice one draws from small series, case reports and expert opinion to handle challenging cases. Current guidelines promote a step-by-step approach, starting with high-dose steroids and increasing drug immunosuppression as needed. This consensus will certainly be maintained in the absence of validated clinical or biological biomarkers predictive of steroid-refractoriness. On the other hand, clinicians confronted with severe irAEs should not discard the possibility to add a cytokine-directed mAb from the beginning of a severe irAE with the putative advantage of "shutting-off" early a rapidly evolving immuno-pathophysiological process, thereby avoiding patient exposure to extended courses of immunosuppression. A good example for first instance aggressive drug immunosuppression is myocardial irAEs. In this case, better efficacy of rapid immunosuppression is presumed due to its fulminant clinical presentation, the high associated morbi-mortality rate, as well as the documented increased risk of adverse outcomes with lower steroid doses compared to high-dose therapy. ${ }^{7}$ For other irAEs, biomarker-based approaches are already being explored. For example, in ICI-related colitis, ulcerative endoscopic finding have recently been suggested as predictive surrogate markers for steroid-refractoriness. ${ }^{8} \mathrm{~A}$ recent study on 90 colic biopsies from patients with ICI-related colitis showed different profiles of immune infiltrates: $27 \%$ of patients had immune infiltrates with predominant intraepithelial lymphocytosis, whereas $73 \%$ of patients had predominant monocytic/neutrophilic infiltrates. ${ }^{8}$ Such patterns could be considered as rational "target" tools to personalize a "shut-off" strategy 
based on the type of immune infiltrate: For a predominant T-cell infiltrate, a T-cell-directed therapy such as anti-IL-6, anti-IL-1R or anti-IL-12/23 blockade strategy could be an optimal approach. A prominent B/plasma cells infiltrate might be optimally targeted by an anti-B-cell strategy (anti-CD20 and/or anti-BAFF blockade). An infiltrate with a predominant neutrophilic/monocyte pattern with or without granulomas could be optimally targeted by an anti-TNFa strategy. Lastly, the difficulty to obtain a biopsy across clinical contexts and depending on the organs involved, as in the case of neurological, rheumatological, ocular irAEs is recognized. The use of a cytokine-directed mAb, targeting IL-6, TNF $\alpha$ and/or IL-1 pathway is still an upfront option to consider in theses cases, as it will be discussed later on.

For the most part, the safety profile of biologic and non-biologic agents used in primary AIDs extrapolated to cancer patients is still incompletely clear. Some of these drugs are considered to have a low likelihood of adverse impact on cancer response, while others may adversely affect T-cell antitumor response and consequently cancer prognosis. Altogether, their use outside of clinical trials should be advised and monitored by specialists in clinical immunology and discussed in light of cancer prognosis, anticipated time of onset of the chosen drugs, and their respective side effect profiles. Knowledge extrapolated from solid organ transplant patients treated with ICIs supports a significant impact of calcineurin inhibitors (CNI) and mycophenolate mofetil (MMF) on the T-cell response. Even so, the latter is already advised as second line immunosuppressive drugs in current guidelines. However, in our opinion, they should be avoided in immunogenic tumors, especially if a curative intent is at stake, such as in advanced melanoma patients. Knowing the role of IL-6 as a major acute inflammatory phase mediator, in cytotoxic T-cells differentiation, but also its protumor properties, an IL-6 targeting strategy constitutes a robust substitute to older immunosuppressive drugs, without compromising the efficacy of immunotherapy. ${ }^{9,10}$

Limitations of such strategies regarding their cost and financial impact on health care systems should be acknowledged. Nevertheless, if the strategy is effective, such costs might be amortized thanks to decreased morbidity. In any case, they should be considered in light of the already high costs ensuing from ICI therapies. Prospective clinical trials answering these open questions are urgently advocated, due to the rapid expansion of cancer immunotherapy. Nevertheless, most of these toxicities are so rare that clinical trials are almost inconceivable. This is why it is essential to actively report irAEs to competent national authorities and to publish them in the medical literature, along with empirically treated cases and case series. 
The following section provides an overview of standard and off-label agents used to treat severe/refractory irAEs as an adjunct to corticosteroids. In principle, we propose to continue each such therapy until the complete resolution of the respective irAE (Table 1).

\section{Corticosteroids}

Due to their rapid action and convenient use, corticosteroids are still considered the first-line treatment of severe irAEs. Commonly used regimens are oral prednisone (1 to $2 \mathrm{mg} / \mathrm{kg}$ ) or parenteral methylprednisolone (bolus range of 125 to $1000 \mathrm{mg}$ ). High-dose corticosteroids carry an inherent risk of infection and metabolic disturbances (iatrogenic Cushing's syndrome), and therefore weaning should be started at early signs of recovery, but over an extended over a period of 4 to 6 weeks to avoid flare phenomena associated with the long half-lives of ICIs antibodies. $^{4}$

Calcineurin inhibitors (CNI), azathioprine (AZA), mycophenolate mofetil (MMF) and infliximab

Treatments used for inflammatory bowel disease (IBD) and autoimmune hepatitis (AIH) have been used by extrapolation to treat colitis and hepatitis resulting from checkpoint blockade. However, the endoscopic and histologic features of irAEs sometimes do not fully overlap with the features seen in primary autoimmune/inflammatory diseases. ${ }^{11}$ In general, ipilimumabinduced colitis is characterized by lymphocytic and/or neutrophilic infiltrates, whereas the histologic picture of Crohn's disease includes non-necrotizing granulomas as a prominent feature. Even so, severe and refractory irAE colitis can be treated with infliximab (a chimeric monoclonal anti-TNF $\alpha$ antibody) at a single dose of $5 \mathrm{mg} / \mathrm{kg}$, by analogy with Crohn's disease $^{12}$. This treatment has been shown to be highly effective for corticosteroid-refractory colitis, with rapid responses occurring in 1 to 3 days. In some relapsing cases, a second dose is necessary after 2 weeks. Maintenance treatment should be reserved for chronic and relapsing cases. MMF is considered a second-line treatment for ICI-induced hepatitis; by analogy with $\mathrm{AIH}$, azathioprine could also be a reasonable treatment option. ${ }^{12} \mathrm{CNI}$ have been used as adjunct treatment for corticosteroid-refractory colitis and hepatitis, although evidence supporting their use in this setting is not well documented. ${ }^{13}$ Plasma dosing and levels-based scheduling of 
MMF and CNI administration should be performed in order to confirm the therapeutic doses and avoid toxicity.

Beyond the aforementioned tested immunosuppressive/immunomodulatory drugs to treat severe/refractory irAE cases, additional options can be envisaged by extrapolating knowledge from the treatment of primary AIDs (Figure 1).

\section{Anti-IL-1 blockade}

IL-1 is one of the main cytokines present during the acute phase of inflammation. Preclinical data have identified the IL-1beta pathway as an important promoter of tumor progression through stimulation of tumor-associated macrophages (TAMs), myeloid suppressive cells and up-regulation of PD-L1 in tumor cells. ${ }^{14}$ In addition, CNS injury leads to an inflammatory response that is partly mediated by an increase in IL-1 levels through tissue infiltration by neutrophils. ${ }^{13}$ As shown in several animal models, IL-1 receptor antagonists possess CNSprotective properties. ${ }^{15}$ Anakinra, a recombinant IL-1 receptor antagonist, and canakinumab, a monoclonal antibody with anti-IL-1beta activity, are approved for the treatment of rheumatoid arthritis and other auto-inflammatory diseases, respectively. IL-1 blockade is accepted as having no detrimental effect on cancer response. ${ }^{16}$ An anti-IL-1 strategy employing anakinra or canakinumab may find a place as primary therapy for some irAEs, such as acute phase myasthenia gravis (MG), encephalitis, aseptic meningitis, severe arthritis, chronic inflammatory demyelinating polyradiculoneuritis (CIDP), psoriasis, auto-inflammatory diseases, or severe anti-TNF $\alpha$-refractory colitis, pneumonitis and myocarditis. A possible protocol could be anakinra $100 \mathrm{mg}$ once/day or canakinumab 300-600 mg every 8 weeks.

\section{Anti-IL-6 blockade}

Together with IL-1 and TNFa, one of main cytokines in the acute inflammation phase is IL-6. Additionally, IL-6 has been reported to promote cancer development and metastasis, and to function as a main cytokine in the generation of a systemic inflammatory response and the expansion of cancer-related symptoms, leading to the deterioration in physical performance and quality of life. ${ }^{17}$ Furthermore, anti-IL- 6 therapy appears to be very effective for severe IBD that does not respond to traditional therapy targeting $\mathrm{TNF} \alpha{ }^{18}$ 
Consequently, the use of anti-IL-6 therapy as an upfront treatment could be an excellent alternative to anti-TNF $\alpha$ or anti-IL-1 agents for many irAE indications, without compromising the efficacy of immunotherapy. Possible indications include severe irAEs in their acute phase, severe arthritis, uveitis, Graves' orbitopathy, myocarditis, large-vessel vasculitis, severe pneumonitis and MG. ${ }^{19-24}$ A possible protocol might comprise $8-\mathrm{mg} / \mathrm{kg}$ tocilizumabadministered i.v. once per month or $162 \mathrm{mg}$ administered subcutaneously once per week. However, its use should be used carefully in cases of refractory ICI-induced enterocolitis due to a potential increased risk of lower gastrointestinal track perforation, as reported in rheumatoid arthritis patients. ${ }^{25,26}$

\section{Intravenous immunoglobulins (IVIGs)}

IVIGs are the standard treatment for Guillain-Barré syndrome (GBS) as well as subacute and chronic inflammatory demyelinating polyradiculoneuritis (CDIP). Dramatic improvements in ICI-induced cases of GBS or CIPD have been reported using standard approaches with protocols of $400 \mathrm{mg} / \mathrm{kg} /$ day for 5 days. ${ }^{27}$ Immune thrombocytopenia is a rare irAE whose occurrence may cause delays in the instauration of further anticancer treatment and place the patient at life-threatening risk for bleeding, especially in populations with a high prevalence of CNS metastasis, such as melanoma patients. Three-quarters of patients will respond to corticosteroids; refractory cases may require CNI treatment or IVIGs. ${ }^{28}$ Thrombopoietin agonists such as romiplostim have also been used in the setting of anti-PD-1-induced thrombocytopenia. ${ }^{29}$ Use of IVIGs should be limited in view of their intense, albeit shortlasting, effect. Possible indications for IVIGs are GBS, subacute and chronic inflammatory neuropathies, immune thrombocytopenia, facial nerve palsy, MG, transverse myelitis, enteric neuropathy, ocular myositis and encephalitis. ${ }^{30}$ A case of severe corticosteroid-refractory autoimmune neutropenia responding to IVIG following ipilimumab treatment has also been reported. ${ }^{31}$ A possible protocol might be $400 \mathrm{mg} / \mathrm{kg} / \mathrm{day}$ for 5 days once per month for a total of 3 to 4 treatments.

\section{Anti-B-cell strategy}

Autoimmune encephalitis is a rare but dreadful irAE that is often associated with double checkpoint blockade, as reported in different tumor types. Cases have been reported in which 
anti-neural autoantibodies were detected, such as anti-NMDAR ${ }^{32}$ or anti-Hu $\mathrm{Nu}^{33}$; in other cases, such antibodies were undetectable. In several reports, both type of cases (i.e. independently of serologic status), showed an impressive neurologic improvement after treatment with rituximab (anti-CD20 monoclonal antibody); in these cases, patients were mostly unresponsive to corticosteroids and IVIGs. ${ }^{32,34}$ Thus, whether autoantibodies are directly pathogenic (i.e., anti-NMDAR), directed against intra-cytoplasmic antigens (i.e., anti-Hu), or undetectable, rituximab can be considered as a therapeutic alternative, with probably low impact on tumor control. Additionally, rituximab could be an excellent option for ICI-induced AIDs with an autoantibody profile, such as SLE, severe SJS, ANCA-associated vasculitis, cutaneous vasculitis, autoimmune autonomic ganglionopathy (AAG), sensory ganglionopathy, nephritis, MG, transverse myelitis, enteric neuropathy and encephalitis. Furthermore, rituximab can also be used to treat autoimmune hepatitis or refractory hemolytic anemia in patients intolerant or refractory to standard regimens. ${ }^{35}$ Possible protocols are two courses of rituximab $1 \mathrm{~g}$ two weeks apart or $375 \mathrm{mg} / \mathrm{m}^{2}$ once per week for 4 weeks. Other fully human anti-CD20 antibodies are also available: ofatumumab $300 \mathrm{mg}$ on day 1 and $1000 \mathrm{mg}$ on day 2, obinutuzumab 1000 $\mathrm{mg}$ on days 1 and 2, and ocrelizumab $300 \mathrm{mg}$ on days 1 and 4 . Because these new human antiCD20 antibodies seem to have an excellent safety profile and at least similar effectiveness as rituximab, they may provide a possible alternative to rituximab. Belimumab (anti-BAFF mAb) has proven its efficacy in SLE and may be an option as an adjunct to rituximab in severe/refractory autoantibody-mediated irAEs, as this combination may induce a more profound B-cell depletion. A possible deleterious effect on tumor control should lead to a careful assessment of patient's risk and potential benefits.

\section{Anti-IL-17 therapy}

High IL-17 serum levels have been reported during ipilimumab-induced colitis. ${ }^{36}$ Blockade through monoclonal antibodies such as secukinumab may constitute an interesting strategy to manage this toxicity. However, contradictory evidence regarding IL-17 and its implications in promoting tumor growth and metastasis has raised concern. ${ }^{37}$ For example, a patient with metastatic colon cancer (with a mismatch repair-deficient tumor) who initially responded to PD-1 blockade, showed tumor progression after treatment with secukinumab for a psoriatic rash. ${ }^{38}$ In view of the heterogeneous microenvironment across tumor types and individuals, the identification of profiles that might be able to predict the role of IL-17 in tumor control or, conversely, tumor promotion should be pursued. Possible indications for use of anti-IL-17 
therapy are severe psoriasis refractory to anti-TNFa therapy and rheumatoid arthritis. Several mAbs are available and could be used as follows: ixekizumab $80 \mathrm{mg}$ s.c. every two weeks, brodalumab $210 \mathrm{mg}$ s.c. every two weeks and secukinumab $150 \mathrm{mg}$ s.c. every week.

\section{Anti-IL-23/12 therapy}

Ustekinumab is a mAb targeting the common p40 subunit of IL-23 and IL-12). It is approved for the treatment of cutaneous and psoriasis arthritis. In addition, a randomized trial comparing ustekinumab to placebo in the setting of anti-TNF $\alpha$-refractory Crohn's disease showed that at 6 weeks after beginning the drug, one-third of patients experienced a response. ${ }^{39}$ Opposing roles of IL-23 and IL-12 in maintaining outgrowth and dormancy of tumors in mice raise concerns regarding the use of ustekinumab in cancer patients. Nevertheless, most clinical trials did not find unexpected increases in cancer rates across approved indications. ${ }^{40,41}$ In the palliative and refractory irAE setting, ustekinumab treatment may be a conceivable option in selected cases. A possible protocol is: induction dose of $6 \mathrm{mg} / \mathrm{kg}$ i.v. followed by $90 \mathrm{mg}$ every 8 to 12 weeks.

\section{Janus kinase inhibition}

Tofacitinib, a Jak 1/3 inhibitor, is currently used across several rheumatological indications, such as refractory rheumatoid arthritis and ulcerative colitis. ${ }^{42}$ On the other hand, some reports suggest that the risk of lower GI tract perforation associated with tofacitinib treatment among rheumatoid arthritis patients may be more common than with other anti-TNF $\alpha$ agents, suggesting the need for close clinical follow-up during the treatment of ICI-induced colitis. ${ }^{25}$ A possible dosing scheme could be $5 \mathrm{mg}$ or $10 \mathrm{mg}$ twice per day.

\section{Other human anti-TNF $\alpha$ therapies}

Etanercept, adalimumab, certolizumab and golimumab are also available and could be alternatives to infliximab given their excellent safety profiles and proven effectiveness. A published case of corticosteroid- and methotrexate-refractory ICI-induced polyarthritis treated with adalimumab revealed excellent symptomatic improvement together with clinical regression of joint inflammation. ${ }^{43}$ Infliximab is also a rescue option in the treatment of refractory AIH, suggesting that this is another reasonable indication for the other anti-TNF $\alpha$ 
agents. ${ }^{44}$ Possible protocols could be adalimumab $40 \mathrm{mg}$ every two weeks, golimumab $50 \mathrm{mg}$ once per month, etanercept $50 \mathrm{mg}$ once per week or certolizumab $400 \mathrm{mg}$ once per month.

\section{Anti-integrin 4}

Natalizumab is an anti-integrin 4 antibody that is approved for the treatment of multiple sclerosis. It has also been used in a relapsing case of limbic encephalitis in a patient with stage IV SCLC, leading to cognitive improvement without impairing a durable tumor response with a combined checkpoint inhibition. ${ }^{45}$ Vedolizumab is an anti-integrin $\alpha 4 \beta 7$ antibody showing in gut-selective anti-inflammatory activity, with indication for the treatment of refractory IBD. $^{46}$

\section{Plasmapheresis}

A case of MG crisis showed a favorable outcome for at least 6 months after methylprednisolone, IVIGs and 5 courses of plasmapheresis. ${ }^{47}$ As the treatment backbone of GBS relies on the latter, corticosteroid-refractory immune-related AIDP and/or encephalitis patients could be considered as potential candidates for plasmapharesis. ${ }^{48}$

\section{Cyclophosphamide $(\mathrm{CP})$}

Despite its carcinogenic risk, a pulse of CP may be very useful as an induction treatment for remission in multiple severe irAEs, such as severe sarcoidosis, GBS, severe SJS with central and neurological symptoms, AAG, sensory ganglionopathy, polyneuropathy and central neuritis. An induction protocol is $\mathrm{CP}(10$ to $15 \mathrm{mg} / \mathrm{kg}$ ) at weeks $0,2,4,7,10$ and 13 (cumulative dose of $\sim 7 \mathrm{~g}$ ) or $500 \mathrm{mg}$ every two weeks for a total of 6 cures, similar to its use for SLE nephritis.

\section{Cyclophosphamide-rituximab}

In order to achieve rapid remission with minimal exposure to the carcinogenic risk of $\mathrm{CP}$, an appropriate alternative protocol to $6 \mathrm{CP}$ cures could comprise 4 administrations of rituximab $\left(375 \mathrm{mg} / \mathrm{m}^{2}\right)$ at weeks $0,1,2$ and 3 and two administrations of CP (10 to $15 \mathrm{mg} / \mathrm{kg}$ ) at weeks 0 and $2 .{ }^{49}$ 


\section{CONCLUSION}

The development of cancer immunotherapy is one of the major medical breakthroughs. We are only at the beginning of a new era and we are still learning how to make the best use of these novel potent therapies in the management of cancer patients. We have however been facing the appearance of severe toxicity associated with immunotherapy, often with substantial challenges in the management of severe irAEs. Because their clinical course and response to therapy may differ from the ones observed in primary AIDs, we are still learning how to adapt and optimize classic immunosuppressive interventions for the treatment of irAEs. This learning process will take time and will require advances in three areas: (i) the development of biomarkers predictive of steroid-refractoriness, early response to immunosuppressive therapy and safety of ICIs administration; (ii) the development of appropriate therapeutic regimens using classic immunosuppression, i.e. corticosteroids, together with efficient $\mathrm{mAb} / \mathrm{small}$ molecule therapies blocking inflammation; and (iii) the training of a new generation of physicians with specific expertise in immunotherapy.

Because the clinical presentation of irAEs and their severity vary from patient to patient, in part due to intrinsic factors, the identification of genetic, epigenetic or surrogate predictive markers of irAEs development is expected to allow a better safety appraisal of ICI therapies in patients at high risk of irAEs (as well as for those with preexisting AIDs) and to guide the development of preventive interventions. High-throughput RNA sequencing of peripheral mononuclear blood cells or circulating micro-RNAs could be explored to identify predictive signatures of irAE development and be used as non-invasive biomarkers. As a proof of principle, this area of research has already shown promising results in stem cell transplant recipients at risk of graft-versus host disease. ${ }^{50,51}$

Biomarkers are also needed to develop personalized treatment algorithms by choosing the most appropriate "shut-off" strategy to manage severe and refractory irAEs, e.g., according to the immune type of the predominant infiltrate from the affected organ(s), as determined by biopsy. Such approached could inform the direct and selective targeting of main inflammatory cytokines, such as IL-6, TNF $\alpha$ and/or IL-1, together with ICIs discontinuation, without compromising the efficacy of immunotherapy. The expected benefit of this upfront "shut-off" 
strategy is two-fold: blockade of the acute phase of the inflammatory reaction, and inhibition of tumor development promoted by IL-1 and IL-6.

Finally, a new generation of clinicians with specific training and expertise in immunotherapy is needed, due to the evolving complexity of cancer care and the large spectrum of immunerelated toxicities. Furthermore, the proper management of severe irAEs requires the efficient response and concerted decision and of multidisciplinary teams, thus, this type of training crosses the traditional boundaries of medical specialties. Such efforts will ensure that cancer patients benefit from the highest quality care during the ongoing immunotherapy revolution. 
COMPETING INTERESTS: F.M., G.P.S., M.M., M.F., C.R., T.K., O.M., G.C., F.S, J.A.T. and M.O. declare no conflict of interest. S.P. received education grants, provided consultation, attended advisory boards and/or provided lectures for the following organizations: Amgen, AstraZeneca, Boehringer-Ingelheim, Bristol-Myers Squibb, Clovis, Eli Lilly, F. Hoffmann-La Roche, Janssen, Merck Sharp and Dohme, Novartis, Merck Serono, Pfizer, Regeneron and Takeda.

\section{SEARCHSTRATEGY AND SELECTION CRITERIA:}

We searched PubMed for papers published in English between 2010 and 2018. Keywords used included: "checkpoint inhibitor", “immune-related adverse event”, "CTLA4”, "PD-1", "PDL1", "melanoma", "autoimmune hepatitis", "inflammatory bowel disease", "rheumatoid arthritis", “uveitis", “Graves' orbitopathy", "vasculitis", “colitis", ”encephalitis", "pneumonitis", "Guillain-Barré syndrome", “inflammatory demyelinating polyradiculoneuritis", "myocarditis", "myasthenia gravis", “TNFa", "IL-1”, "IL-6”, ”IL-23”, "IL-12”, "corticosteroids", "tocilizumab", "cyclophosphamide”, "rituximab", "natalizumab", "vedolizumab", “etanercept", "adalimumab”, “certolizumab”, "golimumab”, “ustekinumab”, "ixekizumab", “janus kinase inhibitor", “tofacitinib", "brodalumab", “secukinumab", "belimumab", "ofatumumab", “obinutuzumab", “ocrelizumab”, “anakinra”, “canakinumab", "immunolgobulins", "plasmapheresis", and "romiplostim". A paper published earlier than 2010 was identified and included due to its relevance for pathogenesis and management.

\section{AUTHOR CONTRIBUTIONS:}

FM wrote the manuscript and prepared the figures and tables; MO conceived the review, wrote the manuscript and prepared the figures and tables. All authors wrote, commented on and corrected the manuscript.

\section{ACKNOWLEDGMENTS:}

The authors would like to thank Mr Roger Guindon for his help in conception of the figures. GPS is partly supported by a 2016 Leenaards Foundation Fellowship for Academic Advancement in Clinical Medicine. 
Table 1. New therapeutic perspectives for the management of irAEs

Figure 1. Immunosuppressive drug summary according to respective targets. In response to the acute inflammatory phase, many cytokines are continuously secreted, notably IL-1, IL6 and TNF $\alpha$. By analogy with IBD treatment, blocking TNF $\alpha$ by infliximab has been proposed to treat irAE colitis. New humanized anti-TNFa antibodies, such as adalimumab and golimumab, could be alternatives to infliximab, likely exhibiting similar efficiency with fewer allergic side effects. IL-1 and IL-6 are also acute phase targets; blocking these cytokines would impair their stimulatory effect on helper T-cells, B-cells, NK cells, macrophages, plasma cells and hematopoietic stem cells, as well as their endothelial activation properties. This could be more efficient than classically advocated anti-TNF $\alpha$ strategies. Using a "shut-off" interruption strategy by applying an anti-IL6 (tocilizumab) or anti-IL1 (anakinra, canakinumab) agent may have additional advantages because of the pro-tumor and pro-metastatic activities of IL-6 and IL-1. Anti-IL-1 therapy could also be a useful adjunctive treatment in cases of ICI-induced encephalitis in which the inflammatory response is mainly driven by IL-1 increase. B-cell depletion (with rituximab, obinutuzumab, ofatumumab or belimumab) could be helpful for neurological or hematological complications of ICIs, as well as in ICI-induced connective tissue diseases, severe SJS and vasculitis-related irAEs. In addition, IL-12/23 targeting could suppress the acute inflammation phase by impairing the positive stimulatory effect of IL-23 on $\mathrm{TNF} \alpha$ secretion, which could thus be indicated in irAE cases refractory to anti-TNF $\alpha$ agents. Anti-IL-17 strategy could be used to treat cutaneous irAEs, such as anti-TNF $\alpha$-refractory psoriasis-like reactions.

Figure 2. Personalized "shut-off" treatment algorithms for refractory irAEs according to immune-type predominant infiltrate. For a predominant T-cell infiltrate, a T-cell-directed therapy such as anti-IL-6 blockade could be considered, whereas for a prominent B/plasma cell infiltrate component, an anti-B-cell strategy (anti-CD20 and/or anti-BAFF blockade) could be considered. Regarding an infiltrate with predominant neutrophilic and monocytic features with or without granulomatous features, an anti-TNF $\alpha$ strategy would be a plausible option. In case of a clinical and/or biological improvement, another administration could be performed two weeks later if the initial response is not considered sufficient. Also, in case of response, consideration should be given to initiating steroid tapering (over a 4-6-week period). If a tissue biopsy is not available, an anti-IL-6, anti-IL-1 or anti-TNF $\alpha$ strategy are reasonable options. As second-line treatment, an anti-IL1, anti-IL-12/23 or anti-IL-17 agent may be considered 
after a first line with an anti-IL-6 therapy; if not available, then an anti-TNF $\alpha$ strategy may be an option. If no improvement is observed after the second administration repeated after two weeks, a third line should be considered. For that, we propose an anti-integrin 4 agent (Natalizumab) as a first choice; if not available, then a non-selective IS or a Janus Kinase inhibitor could also be considered. If no improvement is observed after the second administration repeated after two weeks, a fourth line could be considered, such as cyclophosphamide 10-15 mg/kg and/or plasmapheresis. The fourth line could be repeated more than twice until irAE resolution. The administration of IVIG could be considered for GBS and CDIP at any moment. 


\section{REFERENCES}

1. Wolchok JD, Chiarion-Sileni V, Gonzalez R, et al. Overall Survival with Combined Nivolumab and Ipilimumab in Advanced Melanoma. N Engl J Med 2017; 377(14): 1345-56.

2. Haanen J, Carbonnel F, Robert C, et al. Management of toxicities from immunotherapy: ESMO Clinical Practice Guidelines for diagnosis, treatment and follow-up. Ann Oncol 2017; 28(suppl_4): iv119-iv42.

3. Puzanov I, Diab A, Abdallah K, et al. Managing toxicities associated with immune checkpoint inhibitors: consensus recommendations from the Society for Immunotherapy of Cancer (SITC) Toxicity Management Working Group. J Immunother Cancer 2017; 5(1): 95.

4. National Comprehensive Cancer Network. Management of Immunotherapy-Related Toxicities. https://www.nccn.org/professionals/physician_gls/pdf/immunotherapy.pdf (accessed February 14, 2018.

5. Horvat TZ, Adel NG, Dang TO, et al. Immune-Related Adverse Events, Need for Systemic Immunosuppression, and Effects on Survival and Time to Treatment Failure in Patients With Melanoma Treated With Ipilimumab at Memorial Sloan Kettering Cancer Center. J Clin Oncol 2015; 33(28): 3193-8.

6. Stroud CR, Hegde A, Cherry C, et al. Tocilizumab for the management of immune mediated adverse events secondary to PD-1 blockade. J Oncol Pharm Pract 2017: 1078155217745144.

7. Mahmood SS, Fradley MG, Cohen JV, et al. Myocarditis in Patients Treated With Immune Checkpoint Inhibitors. J Am Coll Cardiol 2018; 71(16): 1755-64.

8. Geukes Foppen MH, Rozeman EA, van Wilpe S, et al. Immune checkpoint inhibitionrelated colitis: symptoms, endoscopic features, histology and response to management. ESMO Open 2018; 3(1): e000278.

9. Fisher DT, Appenheimer MM, Evans SS. The two faces of IL-6 in the tumor microenvironment. Semin Immunol 2014; 26(1): 38-47.

10. Landskron G, De la Fuente M, Thuwajit P, Thuwajit C, Hermoso MA. Chronic inflammation and cytokines in the tumor microenvironment. J Immunol Res 2014; 2014: 149185.

11. Verschuren EC, van den Eertwegh AJ, Wonders J, et al. Clinical, Endoscopic, and Histologic Characteristics of Ipilimumab-Associated Colitis. Clin Gastroenterol Hepatol 2016; 14(6): 836-42.

12. Cheng $\mathrm{R}$, Cooper $\mathrm{A}$, Kench $\mathrm{J}$, et al. Ipilimumab-induced toxicities and the gastroenterologist. J Gastroenterol Hepatol 2015; 30(4): 657-66.

13. Lucas SM, Rothwell NJ, Gibson RM. The role of inflammation in CNS injury and disease. Br J Pharmacol 2006; 147 Suppl 1: S232-40.

14. Jiang H, Gebhardt C, Umansky L, et al. Elevated chronic inflammatory factors and myeloid-derived suppressor cells indicate poor prognosis in advanced melanoma patients. Int J Cancer 2015; 136(10): 2352-60.

15. Murray KN, Parry-Jones AR, Allan SM. Interleukin-1 and acute brain injury. Front Cell Neurosci 2015; 9: 18.

16. Cappelli LC, Shah AA, Bingham CO, 3rd. Immune-Related Adverse Effects of Cancer Immunotherapy- Implications for Rheumatology. Rheum Dis Clin North Am 2017; 43(1): 65 78.

17. Laird BJ, Fallon M, Hjermstad MJ, et al. Quality of Life in Patients With Advanced Cancer: Differential Association With Performance Status and Systemic Inflammatory Response. J Clin Oncol 2016; 34(23): 2769-75. 
18. Brulhart L, Nissen MJ, Chevallier P, Gabay C. Tocilizumab in a patient with ankylosing spondylitis and Crohn's disease refractory to TNF antagonists. Joint Bone Spine 2010; 77(6): 625-6.

19. Dayer JM, Choy E. Therapeutic targets in rheumatoid arthritis: the interleukin-6 receptor. Rheumatology (Oxford) 2010; 49(1): 15-24.

20. Hirano T, Ohguro N, Hohki S, et al. A case of Behcet's disease treated with a humanized anti-interleukin-6 receptor antibody, tocilizumab. Mod Rheumatol 2012; 22(2): 298-302.

21. Perdan-Pirkmajer K, Praprotnik S, Tomsic M. A case of refractory adult-onset Still's disease successfully controlled with tocilizumab and a review of the literature. Clin Rheumatol 2010; 29(12): 1465-7.

22. Muselier A, Bielefeld P, Bidot S, Vinit J, Besancenot JF, Bron A. Efficacy of tocilizumab in two patients with anti-TNF-alpha refractory uveitis. Ocul Immunol Inflamm 2011; 19(5): 382-3.

23. Perez-Moreiras JV, Alvarez-Lopez A, Gomez EC. Treatment of active corticosteroidresistant graves' orbitopathy. Ophthalmic Plast Reconstr Surg 2014; 30(2): 162-7.

24. Jonsson DI, Pirskanen R, Piehl F. Beneficial effect of tocilizumab in myasthenia gravis refractory to rituximab. Neuromuscul Disord 2017; 27(6): 565-8.

25. Xie F, Yun H, Bernatsky S, Curtis JR. Brief Report: Risk of Gastrointestinal Perforation Among Rheumatoid Arthritis Patients Receiving Tofacitinib, Tocilizumab, or Other Biologic Treatments. Arthritis Rheumatol 2016; 68(11): 2612-7.

26. Strangfeld A, Richter A, Siegmund B, et al. Risk for lower intestinal perforations in patients with rheumatoid arthritis treated with tocilizumab in comparison to treatment with other biologic or conventional synthetic DMARDs. Ann Rheum Dis 2017; 76(3): 504-10.

27. Tanaka R, Maruyama H, Tomidokoro $\mathrm{Y}$, et al. Nivolumab-induced chronic inflammatory demyelinating polyradiculoneuropathy mimicking rapid-onset Guillain-Barre syndrome: a case report. Jpn J Clin Oncol 2016; 46(9): 875-8.

28. Kopecky J, Trojanova P, Kubecek O, Kopecky O. Treatment possibilities of ipilimumab-induced thrombocytopenia--case study and literature review. Jpn J Clin Oncol 2015; 45(4): 381-4.

29. Kanameishi S, Otsuka A, Nonomura Y, Fujisawa A, Endo Y, Kabashima K. Idiopathic thrombocytopenic purpura induced by nivolumab in a metastatic melanoma patient with elevated PD-1 expression on B cells. Ann Oncol 2016; 27(3): 546-7.

30. Pushkarevskaya A, Neuberger U, Dimitrakopoulou-Strauss A, Enk A, Hassel JC. Severe Ocular Myositis After Ipilimumab Treatment for Melanoma: A Report of 2 Cases. $J$ Immunother 2017; 40(7): 282-5.

31. Akhtari M, Waller EK, Jaye DL, et al. Neutropenia in a patient treated with ipilimumab (anti-CTLA-4 antibody). J Immunother 2009; 32(3): 322-4.

32. Williams TJ, Benavides DR, Patrice KA, et al. Association of Autoimmune Encephalitis With Combined Immune Checkpoint Inhibitor Treatment for Metastatic Cancer. JAMA Neurol 2016; 73(8): 928-33.

33. Papadopoulos KP, Romero RS, Gonzalez G, Dix JE, Lowy I, Fury M. Anti-HuAssociated Autoimmune Limbic Encephalitis in a Patient with PD-1 Inhibitor-Responsive Myxoid Chondrosarcoma. Oncologist 2018; 23(1): 118-20.

34. Ito M, Fujiwara S, Fujimoto D, et al. Rituximab for nivolumab plus ipilimumabinduced encephalitis in a small-cell lung cancer patient. Ann Oncol 2017; 28(9): 2318-9.

35. Burak KW, Swain MG, Santodomingo-Garzon T, et al. Rituximab for the treatment of patients with autoimmune hepatitis who are refractory or intolerant to standard therapy. Can J Gastroenterol 2013; 27(5): 273-80. 
36. Callahan MK, Yang A, Tandon S, et al. Evaluation of serum IL-17 levels during ipilimumab therapy: Correlation with colitis. Journal of Clinical Oncology 2011; 29(15_suppl): 2505-.

37. Fabre J, Giustiniani J, Garbar C, et al. Targeting the Tumor Microenvironment: The Protumor Effects of IL-17 Related to Cancer Type. Int J Mol Sci 2016; 17(9).

38. Esfahani K, Miller WH, Jr. Reversal of Autoimmune Toxicity and Loss of Tumor Response by Interleukin-17 Blockade. N Engl J Med 2017; 376(20): 1989-91.

39. Feagan BG, Sandborn WJ, Gasink C, et al. Ustekinumab as Induction and Maintenance Therapy for Crohn's Disease. N Engl J Med 2016; 375(20): 1946-60.

40. Teng MW, Vesely MD, Duret H, et al. Opposing roles for IL-23 and IL-12 in maintaining occult cancer in an equilibrium state. Cancer Res 2012; 72(16): 3987-96.

41. Deepak P, Loftus EV, Jr. Ustekinumab in treatment of Crohn's disease: design, development, and potential place in therapy. Drug Des Devel Ther 2016; 10: 3685-98.

42. Sandborn WJ, Su C, Panes J. Tofacitinib as Induction and Maintenance Therapy for Ulcerative Colitis. N Engl J Med 2017; 377(5): 496-7.

43. Oke AR, Wheater M, Karydis I, Wallis D. Successful use of adalimumab in immune checkpoint inhibitor-associated inflammatory arthritis. Rheumatology Advances in Practice 2018; 2(1): rky001-rky.

44. Weiler-Normann C, Schramm C, Quaas A, et al. Infliximab as a rescue treatment in difficult-to-treat autoimmune hepatitis. J Hepatol 2013; 58(3): 529-34.

45. Hottinger AF, de Micheli R, Guido V, Karampera A, Hagmann P, Du Pasquier R. Natalizumab may control immune checkpoint inhibitor-induced limbic encephalitis. Neurology - Neuroimmunology Neuroinflammation 2018; 5(2).

46. Singh H, Grewal N, Arora E, Kumar H, Kakkar AK. Vedolizumab: A novel antiintegrin drug for treatment of inflammatory bowel disease. J Nat Sci Biol Med 2016; 7(1): 49.

47. Huh SY, Shin SH, Kim MK, Lee SY, Son KH, Shin HY. Emergence of Myasthenia Gravis with Myositis in a Patient Treated with Pembrolizumab for Thymic Cancer. Journal of Clinical Neurology (Seoul, Korea) 2018; 14(1): 115-7.

48. Richard K, Weslow J, Porcella SL, Nanjappa S. A Case Report of Steroid Responsive Nivolumab-Induced Encephalitis. Cancer Control 2017; 24(5): 1073274817729069.

49. Stone JH, Merkel PA, Spiera R, et al. Rituximab versus cyclophosphamide for ANCAassociated vasculitis. $N$ Engl J Med 2010; 363(3): 221-32.

50. Xiao B, Wang Y, Li W, et al. Plasma microRNA signature as a noninvasive biomarker for acute graft-versus-host disease. Blood 2013; 122(19): 3365-75.

51. Atarod S, Ahmed MM, Lendrem C, et al. miR-146a and miR-155 Expression Levels in Acute Graft-Versus-Host Disease Incidence. Front Immunol 2016; 7: 56. 


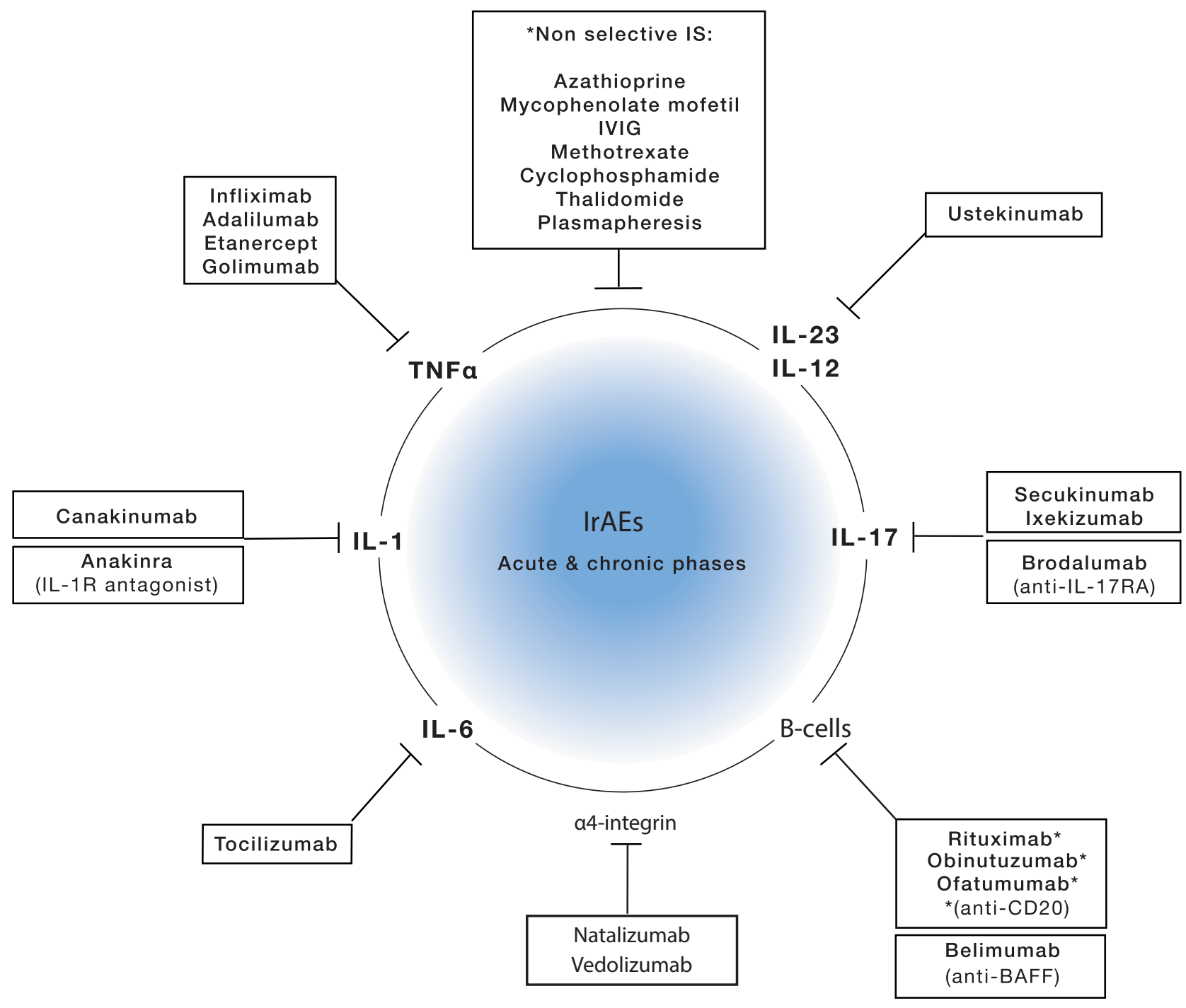


Steroid-refractory irAE/

Severe/rapidly evolving irAE (in selected cases)

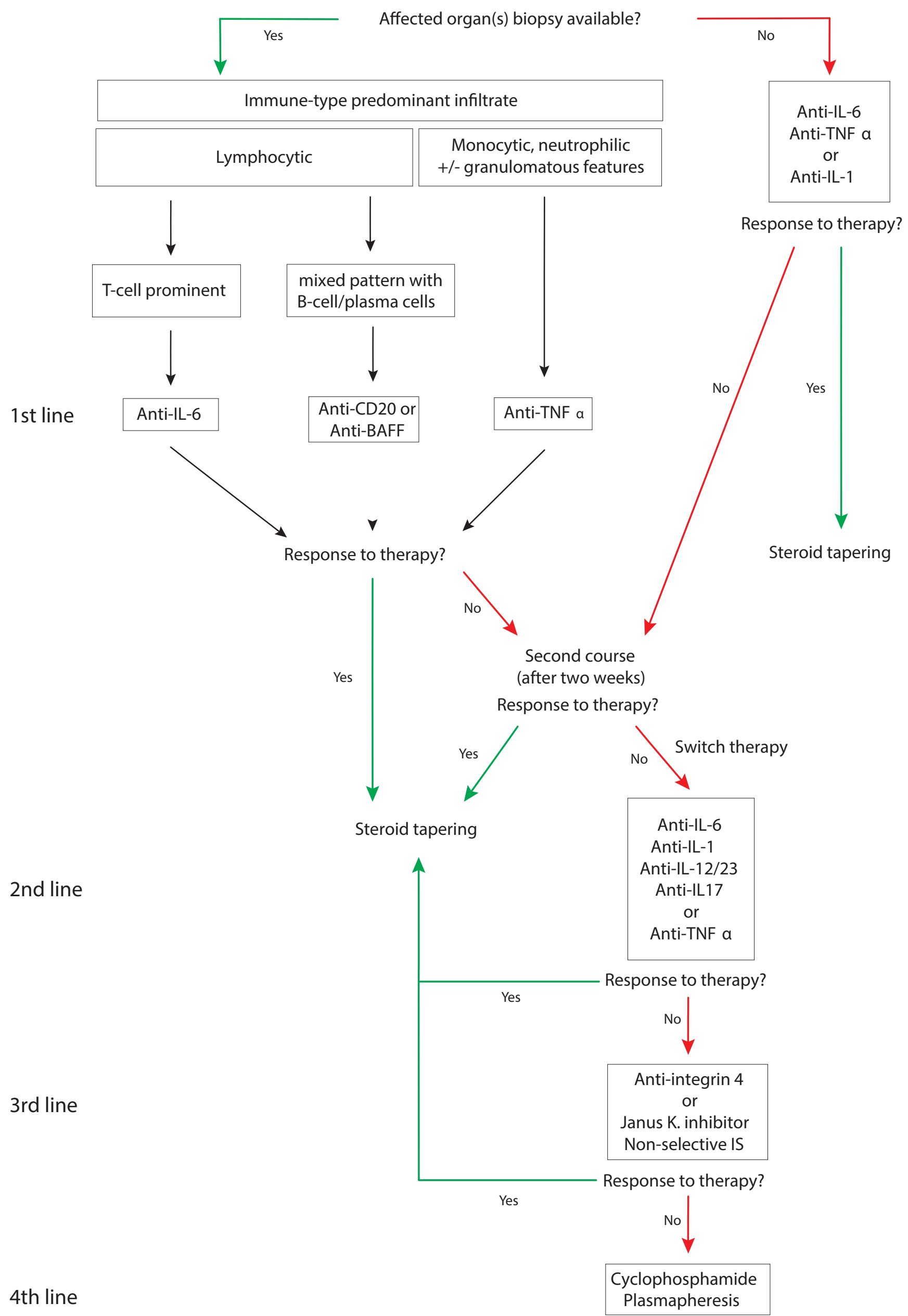




\begin{tabular}{|c|c|c|}
\hline $\begin{array}{c}\text { New therapeutic } \\
\text { options }\end{array}$ & irAE indications & Protocols \\
\hline Anti-IL-1 blockade & $\begin{array}{l}\text { Severe irAE during acute phase } \\
\text { Severe or refractory arthritis } \\
\text { Chronic inflammatory demyelinating } \\
\text { polyradiculonevritis (CIDP) } \\
\text { Psoriasis-like reactions/ } \\
\text { Psoriasis exacerbation } \\
\text { Severe and/or anti-TNFa refractory colitis } \\
\text { Myasthenia gravis } \\
\text { Encephalitis } \\
\text { Aseptic meningitis } \\
\text { Myocarditis } \\
\text { Pneumonitis }\end{array}$ & $\begin{array}{l}\text { - Anakinra: } 100 \mathrm{mg} 1 \mathrm{x} / \mathrm{d} \\
\text { - Canakinumab 300-600 mg 1x/ } 8 \\
\text { weeks }\end{array}$ \\
\hline Anti- IL-6 blockade & $\begin{array}{l}\text { Severe irAE during acute phase } \\
\text { Severe or refractory arthritis } \\
\text { Large vessel vasculitis } \\
\text { Uveitis } \\
\text { Myocarditis } \\
\text { Pneumonitis } \\
\text { Myasthenia gravis }\end{array}$ & $\begin{array}{l}- \text { Tocilizumab at } 8 \mathrm{mg} / \mathrm{kg} \text {, } \\
\text { intravenously } 1 \mathrm{x} / \mathrm{month} \text { or } \\
\text { subcutaneous } 162 \mathrm{mg} 1 \mathrm{x} / \text { week }\end{array}$ \\
\hline $\begin{array}{l}\text { Intravenous } \\
\text { immunoglobulins } \\
\text { (IVIGs) }\end{array}$ & $\begin{array}{l}\text { Guillain-Barré syndrome } \\
\text { Subacute and chronic inflammatory } \\
\text { demyelinating polyradiculonevritis(CIDP) } \\
\text { Subacute and chronic inflammatory } \\
\text { neuropathies } \\
\text { Immune neutropenia } \\
\text { Immune thrombocytopenia } \\
\text { Facial nerve palsy } \\
\text { Myasthenia gravis } \\
\text { Transverse myelitis } \\
\text { Enteric neuropathy } \\
\text { Encephalitis } \\
\text { Aseptic meningitis }\end{array}$ & $\begin{array}{l}400 \mathrm{mg} / \mathrm{kg} / \mathrm{day} \text { for } 5 \text { days, } \\
1 \mathrm{x} / \mathrm{month} \text { for a total of } 3-4 \text { cures. }\end{array}$ \\
\hline Anti-CD20 depletion & $\begin{array}{l}\text { Systemic lupus erythematosus SLE } \\
\text { Severe Sjögren's syndrome SjS } \\
\text { ANCA associated vasculitis } \\
\text { Cutaneous vasculitis } \\
\text { Autoimmune autonomic ganglionopathy } \\
\text { AAG } \\
\text { Sensory ganglionopathy } \\
\text { Nephritis } \\
\text { Myasthenia gravis } \\
\text { Transverse myelitis } \\
\text { Enteric neuropathy } \\
\text { Encephalitis } \\
\text { Aseptic meningitis } \\
\text { Hepatitis }\end{array}$ & $\begin{array}{l}\text {-Rituximab: } 1 \mathrm{~g} \text { every two weeks } \\
\text { for } 2 \text { cures or } 375 \mathrm{mg} / \mathrm{m}^{2} 1 \mathrm{x} / \text { week } \\
\text { for } 4 \text { cures } \\
\text { - Ofatumumab } 300 \mathrm{mg} \text { day } 1 \text { and } \\
1000 \mathrm{mg} \text { day } 2 \\
\text { - Obinutuzumab } 1000 \mathrm{mg} \text { at day } 1 \\
\text { - Ocrelizumab } 300 \mathrm{mg} \text { at day } 1 \\
\text { and day } 4 \text {. }\end{array}$ \\
\hline Anti-IL-17 blockade & $\begin{array}{l}\text { Severe colitis and anti-TNF } \alpha \text { refractory } \\
\text { colitis } \\
\text { Severe or refractory arthritis }\end{array}$ & $\begin{array}{l}\text {-Ixekizumab } 80 \mathrm{mg} \text { sc } 1 \mathrm{x} / 2 \text { weeks } \\
\text {-Brodalumab } 210 \mathrm{mg} \\
\text { weeks }\end{array}$ \\
\hline
\end{tabular}




\begin{tabular}{|c|c|c|}
\hline Anti-TNF $\alpha$ blockade & $\begin{array}{l}\text { Severe colitis } \\
\text { Hepatitis } \\
\text { Severe or refractory arthritis } \\
\text { Nephritis } \\
\text { Uveitis } \\
\text { Pneumonitis } \\
\text { Myocarditis }\end{array}$ & $\begin{array}{l}\text {-Infliximab } 5 \mathrm{mg} / \mathrm{kg} 1 \mathrm{x} / 2 \text { weeks } \\
\text {-Adalimumab } 40 \mathrm{mg} 1 \mathrm{x} / 2 \text { weeks } \\
\text {-Golimumab } 50 \mathrm{mg} 1 \mathrm{x} / \text { month } \\
\text {-Etanercept } 50 \mathrm{mg} 1 \text { one time by } \\
\text { week } \\
\text {-Certolizumab } 400 \mathrm{mg} \text { one time } \\
\text { by month. }\end{array}$ \\
\hline $\begin{array}{ll}\text { Anti-integrin } & 4 \\
\text { blockade } & \\
\end{array}$ & Limbic encephalitis & -Natalizumab $300 \mathrm{mg} 1 \mathrm{x} / \mathrm{month}$ \\
\hline $\begin{array}{l}\text { Anti-IL-23/12 } \\
\text { blockade }\end{array}$ & $\begin{array}{l}\text { Acute phase } \\
\text { Severe or anti-TNF } \alpha \text { refractory colitis } \\
\text { Severe or anti-TNF } \alpha \text { refractory psoriasis } \\
\text { Severe or refractory arthritis }\end{array}$ & $\begin{array}{l}\text {-Ustekinumab } \\
\text { initial dose } 40 \mathrm{mg} \text { than } 45 \mathrm{mg} \text { after } \\
4 \text { weeks and then } 45 \mathrm{mg} \text { every } 12 \\
\text { weeks }\end{array}$ \\
\hline $\begin{array}{ll}\text { Janus } & \text { Kinase } \\
\text { inhibitor } & \end{array}$ & Severe or refractory arthritis & -Tofacatinib $5 \mathrm{mg} \mathrm{2x/day}$ \\
\hline
\end{tabular}

